\title{
A Conceptual Framework for Assessing Motivation and Self-Regulated Learning in College Students
}

\author{
Paul R. Pintrich ${ }^{1,2}$
}

A conceptual framework for assessing student motivation and self-regulated learning in the college classroom is presented. The framework is based on a self-regulatory (SRL) perspective on student motivation and learning in contrast to a student approaches to learning ( $S A L)$ perspective. The differences between SRL and SAL approaches are discussed, as are the implications of the SRL conceptual framework for developing instruments to assess college student motivation and learning. The conceptual framework may be useful in guiding future research on college student motivation and learning.

KEY WORDS: self-regulation; motivation; learning strategies; college students.

The field of research on college and university student motivation and learning is quite diverse and there are many different models and perspectives. A key distinction in the field has been the contrast between two general perspectives, one called the student approaches to learning (SAL) and the other often labeled the information processing (IP) approach (e.g., Biggs, 1993; Dyne et al., 1994; Entwistle and Waterston, 1988). Many of the papers in this special issue take the SAL perspective, as it has been most often used in Europe and Australia. SAL models are usually characterized as being based on bottom-up models derived from in-depth qualitative interviews with students about their own actual motivation, learning,

${ }^{1}$ Combined Program in Education and Psychology, The University of Michigan, Ann Arbor, Michigan.

${ }^{2}$ Correspondence should be addressed to Paul R. Pintrich, Combined Program in Education and Psychology, The University of Michigan, Ann Arbor, Michigan; e-mail: dmoshman1@unl.edu. 
and studying in real college and university contexts (Biggs, 1993; Dyne et al., 1994; Entwistle and Waterston, 1988; Marton and Saljo, 1976). Of course, as noted by many of the researchers in this special issue, SAL models also use quantitative methods, particularly self-report surveys and questionnaires to assess college student motivation and learning.

In contrast, North American researchers have used the information processing (IP) approach more often (e.g., Pintrich et al., 1991, 1993; Weinstein et al., 1988). The IP approach is often described as being derived in a top-down manner from psychological constructs and theories in cognitive and educational psychology and then applied to college student learning using quantitative methods (Biggs, 1993; Dyne et al, 1994; Entwistle and Waterston, 1988). Although many current models of learning in college students are historically derived from an information processing perspective, a more accurate characterization of this perspective now would be to use the term "self-regulated learning" (SRL) perspective (Pintrich, 2000b; Winne and Hadwin, 1998; Zimmerman, 2000).

The SRL perspective has replaced the IP perspective, which is too limited and not reflective of current theory and research. In particular, the SRL perspective takes a much more inclusive perspective on student learning to include not only cognitive, but also motivational and affective factors, as well as social contextual factors (Pintrich, 2000b). These additions help address one of the criticisms of the IP approach that it did not address issues of student motivation (Biggs, 1993). Accordingly, the SRL approach offers a much richer description of college student learning and motivation than earlier IP models. In addition, there is a much stronger empirical base underlying the SRL perspective, given all the recent research on selfregulation and self-regulated learning in different contexts (see Boekaerts et al., 2000).

The purpose of this paper is to present a conceptual framework that is based on a SRL perspective and to discuss its implications for research on college student motivation and learning. Given the theme of this special issue, there is some discussion of general assessment issues, although recent reviews regarding the construct validity of assessments of self-regulated learning (e.g., Pintrich et al., 2000; Winne et al., 2001; Winne and Perry, 2000) provide much more detail. In addition, the relation of the current conceptual framework to our work (e.g., Pintrich et al., 1991, 1993) on the development of the Motivated Strategies for Learning Questionnaire (MSLQ) is discussed. Finally, given that most of the papers in this special issue reflect a SAL perspective, some of the similarities and differences between SAL and SRL models are highlighted in order to spark discussion and guide future research. 


\section{GENERAL ASSUMPTIONS OF A SELF-REGULATED LEARNING PERSPECTIVE}

There are four general assumptions that most SRL models share. One common assumption is the active, constructive assumption that follows from a general cognitive perspective. That is, under a SRL perspective, learners are viewed as active participants in the learning process. Learners are assumed to construct their own meanings, goals, and strategies from the information available in the "external" environment as well as information in their own minds (the "internal" environment). This assumption is shared with advocates of the SAL perspective (Biggs, 1993; Vermunt, 1996), so there is little disagreement between SRL and SAL perspectives regarding the constructive nature of student learning.

A second, but related, assumption is the potential for control assumption. An SRL perspective assumes that learners can potentially monitor, control, and regulate certain aspects of their own cognition, motivation, and behavior as well as some features of their environments. This assumption does not mean that individuals will or can monitor and control their cognition, motivation, or behavior at all times or in all contexts, rather just that some monitoring, control, and regulation is possible. A SRL perspective clearly recognizes that there are biological, developmental, contextual, and individual difference constraints that can impede or interfere with individual efforts at regulation. Some SAL models may stress a learning style approach that assumes more stable and less controllable individual differences in student learning, whereas other SAL models allow for contextual variation and individual control (cf., Biggs, 1993, 2001; Vermetten et al., 1999; Vermunt, 1996).

A third general assumption is the goal, criterion, or standard assumption. SRL models of regulation assume that there is some type of goal, criterion, or standard against which comparisons are made in order to assess whether the learning process should continue as is or if some type of change is necessary. The general example for learning assumes that individuals can set standards or goals to strive for in their learning, monitor their progress toward these goals, and then adapt and regulate their cognition, motivation, and behavior in order to reach their goals. Again, SAL models may adopt this assumption, depending on how they conceptualize student motivation, goals, and strategies. In these SAL models, students could regulate their learning approach to serve different goals in different contexts (Vermetten et al., 1999).

However, in many SAL models, there is a fixed one-to-one correspondence between motivation and strategies for learning, with more extrinsic 
goals linked to surface learning strategies and intrinsic goals linked to deeper learning strategies (Biggs, 1993). However, this type of merger of goals and strategies into approaches to learning (e.g., general surface vs. deep approaches) does not recognize the possibility that students can flexibly combine different goals and strategies in different ways in different contexts. Accordingly, although there is agreement that student goals are important in both perspectives, the SAL perspective often links goals and strategies in a more fixed manner. In contrast, SRL models allow for the possibility of multiple goals within and across students and diversity in the linkages between goals and strategies.

A fourth general assumption of a SRL perspective is that selfregulatory activities are mediators between personal and contextual characteristics and actual achievement or performance. That is, it is not just individuals' cultural, demographic, or personality characteristics that influence achievement and learning directly, nor just the contextual characteristics of the classroom environment that shape achievement, but the individuals' self-regulation of their cognition, motivation, and behavior that mediate the relations between the person, context, and eventual achievement. This assumption is also made in the SAL models. For example, Biggs $(1993,2001)$ presented an explicit model that makes this assumption as do other models from a SAL perspective that show the interactions between contextual factors, student processing, and learning and achievement (e.g., Trigwell et al., 1999).

In summary, the SAL and SRL perspectives are in complete agreement in terms of the first and fourth assumptions regarding the constructivist nature of student learning and the mediational role of motivational and cognitive processes. In contrast, there are potential disagreements concerning the control/regulation assumption and the role of goals in learning. Moreover, as these two assumptions are translated into the building of conceptual models, the development of constructs, and the conduct of empirical research, there is even more potential for differences to emerge. SAL models often derive their basic constructs from a more phenomenological or phenomenographic approach based on students' own reports of their learning and studying processes. In contrast, SRL models derive their constructs from an analysis and application of psychological models of cognition, motivation, and learning. Accordingly, at the conceptual and construct level, there may be even more disagreement and less similarity between SAL and SRL models. The next section presents a conceptual model based on an SRL perspective on college student motivation and learning. Some of the similarities and differences between this SRL model and SAL models are highlighted, as are the implications for assessment. 


\section{A CONCEPTUAL FRAMEWORK FOR SELF-REGULATED LEARNING IN THE COLLEGE CLASSROOM}

Table I displays a framework for classifying the different phases and areas for regulation. This conceptual framework is based on the four assumptions outlined in the previous section, but adds more detail to how selfregulated learning operates in the classroom. The four phases that make up the rows of the table are processes that many models of regulation and self-regulation share (e.g., Zimmerman, 2000) and reflect goal-setting, monitoring, control, and regulation processes. Of course, not all academic learning follows these phases as there are many occasions for students to learn academic material in more tacit or implicit or unintentional ways without self-regulating their learning in such an explicit manner as suggested in the model.

Phase 1 involves planning and goal setting as well as activation of perceptions and knowledge of the task and context and the self in relation to the task. Phase 2 concerns various monitoring processes that represent metacognitive awareness of different aspects of the self and task or context. Phase 3 involves efforts to control and regulate different aspects of the self or task and context. Finally, Phase 4 represents various kinds of reactions and reflections on the self and the task or context. It is important to note that these planning, monitoring, control, and regulation processes can be applied to all four domains listed in Table I. In other words, under this framework, there is the possibility for "regulation" scales for cognition, motivation, behavior, and context, not just one global metacognition or regulation scale.

The four phases do represent a general time-ordered sequence that individuals would go through as they perform a task, but there is no strong assumption that the phases are hierarchically or linearly structured such that earlier phases must always occur before later phases. In most models of self-regulated learning, monitoring, control, and reaction can occur simultaneously and dynamically as the individual progresses through the task, with the goals and plans being changed or updated on the basis of the feedback from the monitoring, control, and reaction processes. In fact, Pintrich et al. (2000) suggest that much of the empirical work on monitoring (Phase 2) and control/regulation (Phase 3) does not find much separation of these processes in terms of people's experiences as revealed by data from selfreport questionnaires or think-aloud protocols. Accordingly, some assessment instruments may not be able to reliably distinguish among these four phases, nor may there be a need to, depending on the conceptual model or research questions under consideration (Pintrich et al., 2000). 


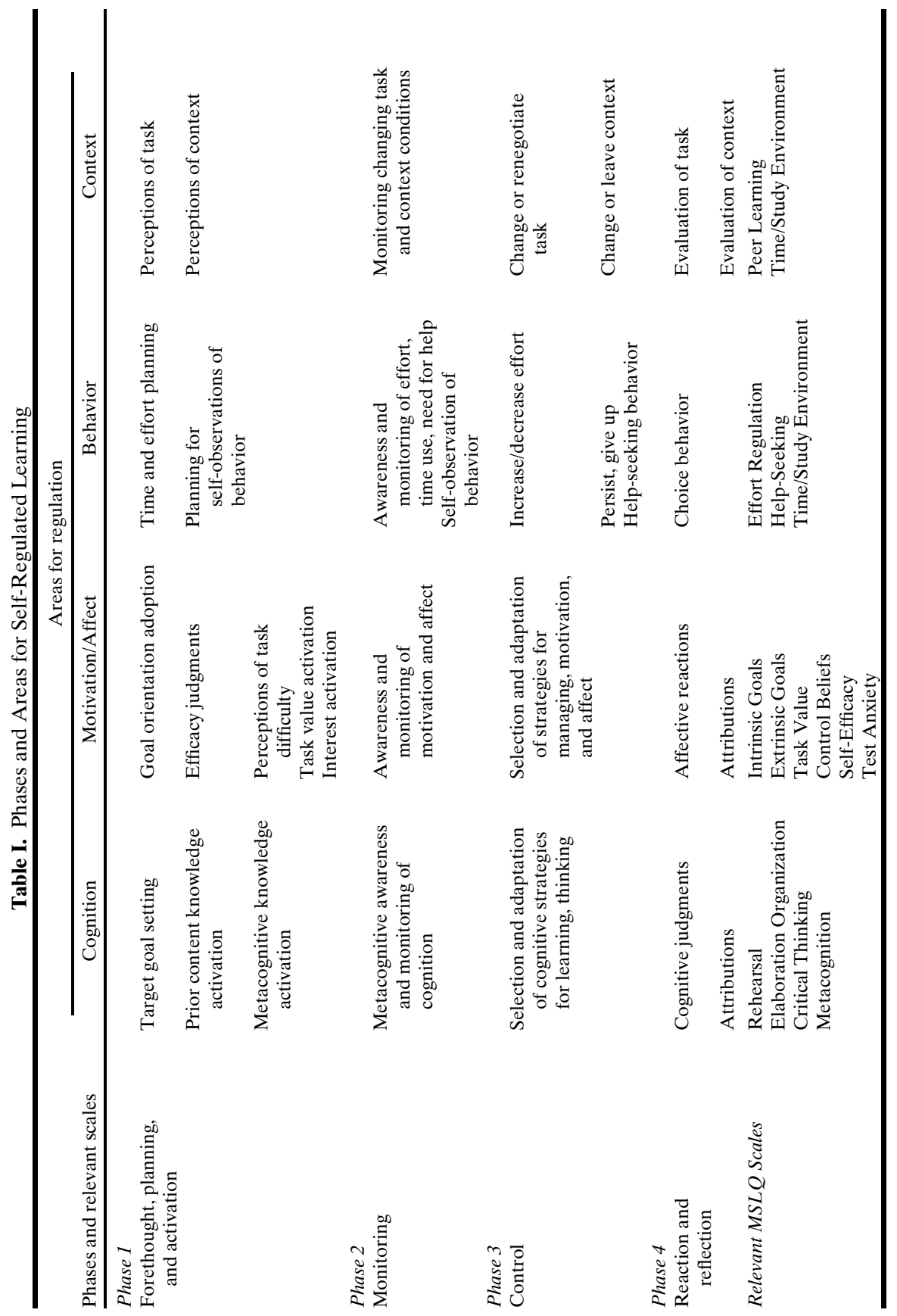


In line with the empirical evidence that demonstrates the difficulty of separating some of the phases, at least using self-report measures, most SAL models would probably not make such fine distinctions between these four different phases. Although students may report doing some planning, monitoring, regulating, and reflecting activities as in Table I, SAL models tend to collapse across these distinctions. In general, SAL models focus on a much larger grain size (Howard-Rose and Winne, 1993; Winne and Perry, 2000) than SRL models, opting for much larger units of analysis such as general approaches to studying or learning, rather than specific phases and the strategies that might be implicated in different phases as in SRL models. In addition, SAL models may not allow for the possibility of regulating different cognitive, motivational, behavioral, or contextual features, instead opting for a general regulation approach or strategy. This may be a key difference between the two perspectives that is insurmountable, as the SAL models tend toward developing a much more synthetic and global construct system, whereas the SRL models tend to rely on a much more analytic approach that can generate many different constructs and categories of student motivation and learning.

Of course, decisions about the appropriate grain size are partially a function of the goals, research questions, and general conceptual framework adopted by researchers. In addition, the capabilities of the different assessment instruments to reliably and validly capture motivational and cognitive processes at different grain sizes must be taken into consideration (Pintrich et al., 2000; Winne et al., 2001; Winne and Perry, 2000). Self-report instruments such as surveys and questionnaires are less able to capture the relevant processes at a very microlevel grain size in terms of the actual cognitive events or tactics used by students as they study and learn. In contrast, self-report instruments may be able to measure general aptitudes or propensities to use different self-regulatory processes (Pintrich et al., 2000; Winne et al., 2001; Winne and Perry, 2000).

The four columns in Table I represent different areas for regulation that an individual learner can attempt to monitor, control, and regulate. The first three columns of cognition, motivation/affect, and behavior reflect the traditional tripartite division of different areas of psychological functioning (Snow et al., 1996), whereas the context column reflects the importance of including social context in our models of SRL. In addition, it should be clear from Table I that regulation is not a domain, and hence is not a separate category of strategy use, but that regulation cuts across the four domains.

Pintrich (2000b) has provided a much more detailed description of each of the rows, columns, and cells in Table I and their role in selfregulated learning. For the purposes of this paper, the following sections focus on the four columns in Table I (not the rows or individual cells) and 
discusses various assessment issues in light of the research and development on the MSLQ (Pintrich et al., 1991, 1993). The last row in Table I lists the scales from the MSLQ that assess different aspects of the model of selfregulated learning.

It is important to note that the development of the MSLQ started in the early 1980s and the instrument in its current form was finalized in 1991 (Pintrich et al., 1991). At that time, our model of college student motivation and learning was based on a simple social cognitive and information processing perspective. However, since that time, there have been many developments in our own research program and in the field in general. It is crucial that it is understood that the MSLQ, which was developed well over 10 years ago, does not represent an instrument designed to assess all components of the current conceptual model in Table I. In some ways, the conceptual model represents a blueprint for the development of new instruments for measuring self-regulated learning in academic contexts. Nevertheless, there is some overlap in the scales of the MSLQ and components of the conceptual model. These are highlighted in the next four sections and are discussed in relation to general assessment issues as well as the similarities and differences between SAL and SRL perspectives.

\section{Regulation of Cognition}

The first column in Table I represents the activities, tactics, and strategies that students engage in to plan, monitor, and regulate their cognition. Planning and forethought activities can include setting specific target or cognitive goals for learning, activating prior knowledge about the material to be studied, as well as activating any metacognitive knowledge students might have about the task or themselves (Pintrich, 2000b). In addition, an important aspect of regulating cognition is the monitoring of cognition. Students have to become aware of and monitor their progress toward their goals, monitor their learning and comprehension, in order to be able to make any adaptive changes in their learning (Bransford et al., 1999; Pintrich, 2000b).

Cognitive control and regulation include the types of cognitive and metacognitive activities that individuals engage in to adapt and change their cognition. As in any model of regulation, it is assumed that attempts to control, regulate, and change cognition should be related to cognitive monitoring activities that provide information about the relative discrepancy between a goal and current progress toward that goal. For example, if a student is reading a textbook with the goal of understanding (not just finishing the reading assignment), then as the student monitors his or her comprehension, this monitoring process can provide the student 
with information about the need to change reading strategies. Finally, as shown in Table I, the reactions and reflections of the student in terms of their cognitive judgments about how they did and their attributions for their performance can be part of their attempts to regulate their learning (Pintrich, 2000b).

One of the central aspects of the control and regulation of cognition is the actual selection and use of various cognitive strategies for memory, learning, reasoning, problem solving, and thinking. In research on self-regulated learning, there are a large number of cognitive and learning strategies that individuals use to help them understand and learn course material. For example, many researchers have investigated the various rehearsal, elaboration, and organizational strategies that learners can use to control their cognition and learning (cf., Pintrich and De Groot, 1990; Pintrich et al., 1993; Pressley and Afflerbach, 1995; Schneider and Pressley, 1997; Weinstein and Mayer, 1986; Zimmerman and Martinez-Pons, 1986).

In our work on the MSLQ, we have used the five scales listed in the last row of the cognitive column in Table I as indicators of cognitive regulation by students. These scales provide some measures of the monitoring and control activities for cognition (see rows 2 and 3 in Table I), but they do not provide any measures of the specific forethought or reaction activities that students might use in the classroom. The scales of rehearsal, elaboration, and organization reflect the use of basic cognitive and learning strategies to understand the material in the course. The metacognition scale represents activities that help the students plan their learning (e.g., set goals), monitor their learning (e.g. monitor reading comprehension), and regulate or change it (e.g., reread text when comprehension fails). The critical thinking scale assesses the extent to which students try to apply prior knowledge to new situations and solve problems, to analyze and evaluate information in a thoughtful manner.

These strategy scales would parallel some of the distinctions between surface and deep approaches to learning from the SAL perspective. In particular, the use of rehearsal strategies in the MSLQ would parallel a more surface approach to learning (or reproductive styles) in SAL models. The other four cognitive scales on the MSLQ should be related to deeper approaches to learning or more transformative, critical thinking, or regulative styles in SAL models (cf., Biggs, 1993; Lonka and Lindblom-Ylanne, 1996; Vermunt, 1996). The main difference between SRL and SAL models here may be in terms of the conceptualization of learning strategies in a SRL model in comparison to learning approaches in SAL models. In this case, the MSLQ conceptualizes and assesses the five cognitive strategies separately from any motivational components. In contrast, the surface and deep approaches to learning fuse motivation and strategies for learning 
into generic learning styles (Biggs, 1993). Moreover, the general conceptual model in Table I proposes a much larger number of potential strategies for controlling and regulating cognition that college students could use in their courses (Pintrich, 2000b). This number goes well beyond the five on the MSLQ and certainly many more than the surface and deep approaches to learning in the SAL models.

Another potential difference may reside in the grain size or domain specificity of the assessments. SAL models, because of their emphasis on general learning approaches and individual differences, may conceptualize and measure motivation and cognition for college or university learning in general, although this assumption is not made in all SAL models (cf., Biggs, 1993, 2001; Vermetten et al., 1999). In contrast, it has always been a strong assumption of our research on the MSLQ that all the scales are operationalized at the course level. We have always assumed that students may use different strategies for different courses and that their motivation for different courses certainly varies. This assumption has been supported in our empirical work (VanderStoep et al., 1996; Wolters and Pintrich, 1998) and raises questions about the validity and utility of measuring student motivation or self-regulation at a more global level, such as for college in general. Of course, both SRL and SAL perspectives realize that strategies and tactics can vary by task and therefore are likely to vary within courses as well, raising a number of difficulties for the validity of self-reports of course strategy use (Winne et al., 2001; Winne and Perry, 2000). Nevertheless, in terms of the utility and practical applications of self-reports (Pintrich et al., 2000), we believe the course level is a good compromise between an overly global level focused on college learning in general and a more microanalytic level focused on different tasks within a course.

In summary, the conceptual framework in Table I proposes that there are a number of different strategies that college students may use to regulate their cognition in university courses. These strategies are assumed to be potentially under the control of the individual, although it is clear that many of them may be used more implicitly without much thought or control. This SRL model hypothesizes that there are many more strategies that students may use to regulate their cognition than the two general approaches to learning (surface and deep) that are most commonly used in SAL models. Besides this key difference in number of strategies, most SRL models (see Weinstein et al., 1988, for an exception) propose that strategies are best measured at some level of domain-specificity such as at the course level (as in the MSLQ, Pintrich et al., 1991,1993) or at a more microanalytic level in terms of specific tasks (Winne et al., 2001; Winne and Perry, 2000). In contrast, some SAL models, but not all, use a more individual difference 
approach that operationalizes learning at a more generic university level. These differences in grain-size and domain-specificity assumptions makes the SRL and SAL approaches somewhat incommensurable in terms of developing common construct lists or common instruments.

\section{Regulation of Motivation and Affect}

In the same manner that learners can regulate their cognition, they can regulate their motivation and affect. This aspect of self-regulation is sometimes discussed under the general heading of volitional control (e.g., Boekaerts, 1993; Corno, 1993; Garcia et al., 1998; Kuhl, 1984). However, in the model in Table I, control and regulation of motivation and affect is just another aspect of self-regulation and there is no reliance on the term volitional control (Pintrich, 1999a, 2000b). Nevertheless, the strategies that are often labeled as volitional control strategies are included in the model in Table I. As in the cognitive column, it is assumed that the motivational beliefs and motivational strategies are domain or course specific and should be measured at some level below the general college or university level.

Regulation of motivation and affect would include attempts to regulate various motivational beliefs that have been discussed in the achievement motivation literature (Pintrich and Schunk, 2002; Wolters, 1998) such as goal orientation (purposes for doing task), self-efficacy (judgments of competence to perform a task), perceptions of task difficulty, task value beliefs (beliefs about the importance, utility, and relevance of the task), and personal interest in the task (liking of content area, domain). Besides these important motivational beliefs, students can attempt to control their affect and emotions through the use of various coping strategies that help them deal with negative affect such as fear and anxiety (Boekaerts, 1993; Boekaerts and Niemivirta, 2000).

These motivational self-regulatory strategies include attempts to control self-efficacy through the use of positive self-talk (e.g., "I know I can do this task," see Bandura, 1997). Students also can attempt to increase their extrinsic motivation for the task by promising themselves extrinsic rewards or making certain positive activities (taking a nap, watching TV, talking with friends, etc.) contingent on completing an academic task (Kuhl, 1984; Wolters, 1998; Zimmerman and Martinez-Pons, 1986). Wolters (1998) found that college students intentionally try to evoke extrinsic goals such as getting good grades to help them maintain their motivation. Students also can try to increase their intrinsic motivation for a task by trying to make it more interesting (e.g., "make it into a game," Sansone et al., 1992; Wolters, 
1998) or to maintain a more mastery-oriented focus on learning (Wolters, 1998). Finally, Wolters (1998) found that college students would try to increase the task value of an academic task by attempting to make it more relevant or useful to them or their careers, experiences, or lives. In all these cases, students are attempting to change or control their motivation in order to complete a task that might be boring or difficult.

In addition, there are strategies students can use to try to control their emotions that might differ from those that they use to control their efficacy or value (Boekaerts, 1993; Boekaerts and Niemivirta, 2000; Corno, 1993; Kuhl, 1984; Wolters, 1998). Self-talk strategies to control negative affect and anxiety (e.g., "don't worry about grades now," "don't think about that last question, move on to the next question") have been noted by anxiety researchers (Zeidner, 1998). Students also may invoke negative affects such as shame or guilt to motivate them to persist at a task (Wolters, 1998). Defensive pessimism is another motivational strategy that students can use to actually harness negative affect and anxiety about doing poorly in order to motivate them to increase their effort and perform better (Garcia and Pintrich, 1994; Norem and Cantor, 1986). Self-handicapping, in contrast to defensive pessimism, involves the decrease of effort (little or no studying) or procrastination (only cramming for an exam, writing a paper at very end of deadline) in order to protect self-worth by attributing the likely poor outcome to low effort, not low ability (Garcia and Pintrich, 1994; Midgley et al., 1996).

After students have completed a task, they may have emotional reactions to the outcome (e.g., happiness at success, sadness at failure) and reflect on the reasons for the outcome-that is, make attributions for the outcome (Weiner, 1986). Following attribution theory, the types of attributions that students make for their success and failure can lead to the experience of more complicated emotions like pride, anger, shame, and guilt (Weiner, 1986). As students reflect on the reasons for their performance, both the quality of the attributions and the quality of the emotions experienced are important outcomes of the self-regulation process. Individuals can actively control the types of attributions they make in order to protect their self-worth and motivation for future tasks (Pintrich, 2000b).

The original model that guided the development of the MSLQ led to the construction of scales that only focused on measuring students' motivational beliefs (five scales) and one emotion (test anxiety, see last row in motivation/affect column in Table I). There are no scales on the current MSLQ that assess any strategies to control motivation or affect, unlike the cognitive scales on the MSLQ that do assess some strategies to regulate cognition. That is, the motivation items only ask students about their motivational beliefs for the course, not any self-regulatory 
strategies students might use to control their motivation or emotion in the course. The two MSLQ scales about goals and purposes for doing work in the course reflect intrinsic and extrinsic motivation as well as mastery and performance goals. This distinction parallels to some extent the SAL distinction between interest in the content and a goal of mastery in the deep approach to learning, and an extrinsic orientation to the task in a surface approach (Biggs, 1993). However, as noted above, the MSLQ maintains separate scales for the motivational goals and cognitive strategies, whereas the SAL approach tends to fuse the goals and strategies into the surface and deep-processing approaches.

The MSLQ also includes measures for student self-efficacy and control of learning, reflecting a general expectancy component of motivation (Eccles et al., 1998). The self-efficacy scale represents students' judgments of their capability to do the course work; the control of learning scale reflects the perception that students have internal control over their own learning and effort. Finally, test anxiety is also measured on the MSLQ, representing students' worry and concern about doing well on exams. In most SAL models there does not seem to be equivalent constructs that are measured, reflecting a major difference in the conceptualization of motivation from SRL models. The absence of efficacy or general expectancy components in the SAL models seems to be a serious omission, particularly given how closely efficacy is tied to actual performance, achievement, and self-regulation of behavior (Bandura, 1997; Pintrich, 1999b, 2000b; Pintrich and Schunk, 2002; Schunk and Ertmer, 2000). In fact, recent work in the expectancy-value tradition of motivation suggests that task value is more closely related to choice of activities, including course enrollment decisions, but once enrolled in a course, efficacy beliefs are a much better predictor of performance than value (Eccles et al., 1998). Accordingly, it seems important to include self-efficacy or expectancy constructs in our models of college student learning.

In summary, both SAL and SRL models do include constructs regarding students' goals for learning, albeit they conceptualize and measure them somewhat differently. However, most SAL models do not include constructs related to self-efficacy or expectancy, reflecting a limited view of motivation. Finally, the MSLQ does not include any measures of students' attempts to monitor, control, and regulate their motivation or affect, making it a limited instrument in terms of assessing important motivational and affective self-regulatory strategies. These strategies seem to be very important in self-regulated learning (Boekaerts and Niemivirta, 2000; Corno, 1993; Garcia et al., 1998; Wolters, 1998) and both SRL and SAL models should include them in their conceptual frameworks and measurement instruments. 


\section{Regulation of Behavior}

Regulation of behavior is an aspect of self-regulation that involves individuals' attempts to control their own overt behavior. Models of intentions, intentional planning, and planned behavior (e.g., Ajzen, 1988; Gollwitzer, 1996) have shown that the formation of intentions are linked to subsequent behavior in a number of different domains. In the academic learning domain, time and effort planning or management are the kinds of activities that are part of behavioral control (see Table I). Effort control involves attempts to control effort in order to do well in the course. Time management involves the making of schedules for studying and allocating time for different activities, which is a classic aspect of most learning and study skills courses (see Hofer et al., 1998; McKeachie et al., 1985; Pintrich et al., 1987; Simpson et al., 1997). Zimmerman and Martinez-Pons (1986) have shown that self-regulating learners and high achievers do engage in time management activities. As part of time management, students also may make decisions and form intentions about how they will allocate their effort and the intensity of their work.

Another behavioral regulatory strategy that can be very helpful for learning is help-seeking. It appears that good students and good selfregulators know when, why, and from whom to seek help (Karabenick and Sharma, 1994; Newman, 1998; Ryan and Pintrich, 1997). Help-seeking is listed here as a behavioral strategy because it involves the person's own behavior, but it also involves contextual control because it necessarily involves the procurement of help from others in the environment and as such is also a social interaction (Ryan and Pintrich, 1997). The inclusion of help-seeking as a social interaction reflects the importance of considering the social nature of learning.

The MSLQ has scales that reflect how students try to regulate their effort in the face of difficult, boring, or uninteresting tasks. In this case, the students are trying to regulate their behavior in terms of their effort, which is often included as a strategy in volitional control models (Corno, 1993; Garcia et al., 1998). In addition, the MSLQ has a scale focused on time management, called time/study environment (see Table I), which includes attempts to manage the overall study environment as well as time schedules. The attempts to manage the study environment is conceptually in the area of contextual regulation (see Table I and next section), but in factor analysis, the time regulation and study environment regulation items are always loaded together, so we created just one scale on the MSLQ for these two strategies. Finally, the MSLQ has a scale about the effective use of help-seeking for academic learning. 
SAL models generally do not have these types of scales as they focus on cognitive regulation, not behavioral regulation (for an exception see Vermetten et al., 1999). However, there does not seem to be any strong conceptual or theoretical reason they could not be included in SAL models. The general capability to control one's effort and persistence in the face of difficult, boring, or low-value tasks is an important self-regulatory strategy. Most college students encounter situations that call for self-regulation of this sort. In addition, as they have more choice and control in their lives and multiple academic, social, and personal demands, college students must learn to manage their time and effort well in order to be successful. Finally, given the social nature of learning, the ability to seek help from peers as well as instructors and other staff can be crucial to success in college. In summary, these strategies should be included in our models of self-regulated learning and in our instruments to assess college student learning (Pintrich, 2000b).

\section{Regulation of Context}

Contextual control and regulatory processes involve efforts to control and regulate the tasks and context the college student confronts in the classroom. In comparison to control and regulation of cognition, motivation, and behavior, control of the tasks or context may be more difficult because they are not always under direct control of the individual learner. Models of volitional control usually include a term labeled environmental control that refers to attempts to control or structure the environment in ways that facilitate goals and task completion (Corno, 1993; Kuhl, 1984). In terms of self-regulated learning, most models include strategies to shape or control or structure the learning environment as important strategies for self-regulation (Zimmerman, 1998).

In the traditional classroom, the instructor controls most of the aspects of the tasks and context. Therefore, there may be little opportunity for students to engage in contextual control and regulation. However, in more student-centered classrooms, students are asked to do much more actual control and regulation of the academic tasks and classroom climate and structure. They often are asked to design their own projects and experiments, work together in collaborative or cooperative groups, design how their groups will collect data or perform the task, develop classroom norms for discourse and thinking, and even work together with the teacher to determine how they will be evaluated on the tasks. These types of classrooms obviously offer a great deal more autonomy and responsibility to the students and they provide multiple opportunities for contextual control and regulation. 
In postsecondary settings, students have much more freedom to structure their environment in terms of their learning. Much of the learning that goes on takes place outside the college lecture hall or classroom, and students have to be able to control and regulate their study environment. Monitoring of their study environment for distractions (music, TV, talkative friends or peers) and subsequent attempts to control or regulate their study environment to make it more conducive for studying (removing distractions, having an organized and specific place for studying) are means to facilitate learning through self-regulation (Hofer et al., 1998; Zimmerman, 1998). In addition, the ability to work well with peers in study groups or cooperative learning groups can be important as more and more college courses require peer interaction and peer learning.

The MSLQ has a scale for peer learning that represents our attempt at measuring how effective an individual student is in using peers as a resource for learning. In addition, as noted in the previous section, there is a scale on the regulation of the study environment (combined with time management, see Table I). Again, most SAL models do not include these types of contextual strategies, but if SAL models are "relational" as suggested by Biggs (1993), then how the individual regulates the context would be an important aspect of learning in the context. Moreover, as noted in Table I, an important aspect of self-regulating the context is the students' perceptions of the task and context and their understanding and monitoring of the norms of the context. In general, SRL models have not included this aspect and the MSLQ has no items reflecting these processes. SAL models do include them to some extent, at least in terms of the general idea that student learning is in relation to how they construct meaning for the tasks in the context (Biggs, 1993). In summary, both SRL and SAL models would do well to include these types of contextual control strategies in their models and assessment instruments.

\section{CONCLUSIONS AND FUTURE DIRECTIONS}

The general conceptual model provides a SRL perspective on college student motivation and learning. It offers a broad outline of the different types of self-regulatory strategies that college students might use to control their own cognition, motivation, affect, and behavior, as well as the college context. As such, it provides a blueprint for the future development of assessment instruments to measure these different strategies. The MSLQ (Pintrich et al., 1991, 1993) only measures a small portion of the potential self-regulatory strategies suggested by the model. SAL models and their accompanying instruments measure some of the components in Table I, but 
not all of them, and, more importantly, there are some major differences in how the components are conceptualized and measured. There is a clear need for more research on the model and the accompanying development of assessment instruments to test the model.

At the same time, there are many conceptual and methodological issues that must be considered in the development of self-report questionnaire instruments to assess self-regulated learning (Pintrich et al., 2000; Winne et al., 2001; Winne and Perry, 2000). Self-report instruments can be developed that are valid and reliable, but there are limitations in their use. One of the most important concerns the grain size or resolution of the instrument. There seems to be an emerging consensus (e.g., Pintrich et al., 2000; Winne et al., 2001; Winne and Perry, 2000) that self-report questionnaires can assess aptitudes or propensities to use self-regulatory strategies in SRL models or different approaches to learning in the SAL models. However, it is clear that self-report questionnaires are not very good at capturing the actual events or on-going dynamic processes of self-regulation. Other more process-oriented measures are required such as stimulated recall, on-line measures, traces, observations, reaction times, and other experimental methods to actually measure self-regulatory events (Pintrich et al., 2000; Winne et al., 2001; Winne and Perry, 2000). Of course, some of these measures have less practical utility than self-report questionnaires, so questionnaires still have a role to play in research on self-regulated learning (Pintrich et al., 2000).

Self-report questionnaires, such as the MSLQ or other instruments developed from a SAL perspective, can provide information about student motivation in the college classroom as well as general capabilities for selfregulation. The key issues for assessment really revolve around questions of construct validity, which include the theoretical and conceptual definition of the construct and the adequacy of the empirical evidence that is offered in support of the instrument (Pintrich et al., 2000). Without a strong framework it is very difficult to interpret the empirical evidence regarding the reliability and validity of the instrument (Messick, 1989; Pintrich et al., 2000). This caution is important for all models and instruments regardless of whether they were developed under either a SRL or SAL perspective.

The proposed model of self-regulation does provide a conceptual model of college student motivation and regulation that is based in a psychological analysis of academic learning. In addition, there is fairly wide empirical support from both laboratory and field-based studies for SRL models of this type (Pintrich, 2000b). The model should provide guidance and support for the evaluation of the empirical evidence in relation to the construct validity of assessment instruments such as self-report questionnaires as well as other types of measures of self-regulated learning. This should be 
helpful in developing valid assessments of college student motivation and self-regulated learning.

Beyond the assessment issues, the model does propose constructs that overlap with some constructs that are derived from SAL models. As noted earlier, some of the cognitive and behavioral self-regulatory strategies in Table I overlap with constructs from the SAL models. In addition, the model shares some basic assumptions with SAL models about the constructivist nature of learning and the important mediational role of student motivation and self-regulation. However, it differs from some SAL models by suggesting a much more differentiated and detailed framework for understanding student motivation and learning. It proposes many different constructs, strategies, and tactics in contrast to a more general SAL framework that includes more general constructs and approaches to learning.

At the same time, the model proposed here, as well as the general SRL perspective, is decidedly based on a scientific and psychological approach to student motivation and learning. This more top-down approach is often rejected in the SAL perspective and in some SAL models (Biggs, 1993; Entwistle and Waterston, 1988) in favor of a more qualitative and phenomenological approach to student learning. Although many of the basic assumptions of both approaches are similar and the constructs generated do overlap to some extent, there can still be some serious disagreements between the two perspectives that make it difficult to synthesize them into a general model of college student motivation and learning.

In particular, if SAL models rely exclusively on a phenomenological approach that privileges students' qualitative reports of their own motivation and learning and do not attempt to link these data to any larger psychological system, then SRL and SAL models will continue to be incommensurable in some ways. This division may be reflective of a larger philosophical chasm between a general postmodern approach and a scientific approach. Some SAL models may be satisfied with qualitative descriptions of student motivation and learning and eschew any attempts to link these data to more general psychological models. In this manner, they are following a more postmodern approach to understanding how students construct their own "folk theories" about motivation and learning. Moreover, from a strong postmodern perspective, the understanding of these folk theories is what is most important and all that really matters.

In contrast, the scientific perspective of SRL models assumes that data generated by students on their motivation and learning, whether through self-report questionnaires or rich, qualitative interviews or any other methods, should map onto psychological models of motivation and learning. It is the main goal of SRL models to build and test these models empirically, both in the laboratory and in the classroom. In fact, although the focus of 
the research is on motivation and learning in the real setting of the college classroom, this does not mean that general psychological theories, models, and constructs developed by cognitive, social, or motivational psychologists in more experimental settings do not apply. The cognitive and motivational systems should be the same given that the research focuses on individuals with the same basic biological and physiological systems. Accordingly, there should not be models that apply to student motivation or learning in the laboratory and completely different ones that apply to student motivation or learning in the college classroom. Of course, the challenge for educational research is to determine how the models and constructs apply and how they can best be used to understand student motivation and learning in the classroom context.

Moving beyond this philosophical difference, SRL and SAL models may be incommensurable in terms of the choice of grain size. SAL models tend to emphasize a more global and holistic approach to describing student motivation and learning that highlights general student approaches to learning. This has the advantage of being relatively simple and easy to understand, especially for faculty who are not researchers on college student motivation and learning. This is particularly helpful in faculty development efforts to improve college and university teaching. The general distinction between surface and deep-processing approaches to learning resonates with faculty and can help them understand student motivation and learning in a way that they can readily use and apply in their own classroom. It provides a common language and framework that researchers, faculty development experts, and faculty can use to improve college and university teaching. In this way, it is much more applicable to educational improvement and development efforts (Biggs, 2001).

In contrast, SRL models may provide a larger number of constructs at a smaller grainsize that describe student motivation and cognition in all its complexity. However, these models are often quite cumbersome and too difficult to use in faculty development efforts. The terminology is foreign and often too complex for faculty who lack prior knowledge in education or psychology. In this sense, the choice of grain-size may be a function of the goals of the researchers in terms of their interest in faculty development and the improvement of university teaching and learning in comparison to those interested in more basic research on college student motivation and learning.

Of course, there should not be such a large gap between these different researchers and there should be ways in which both types of goals can be accomplished. The classic dichotomy between applied and basic research is no longer a viable one for research in the social sciences; research in educational psychology should adopt a use-inspired basic research model 
(Pintrich, 2000a). In this type of research, there are two goals that are pursued simultaneously, one focused on scientific understanding and the other focused on providing useful information that can help solve practical problems. Stokes (1997) called this working in Pasteur's quadrant, after Louis Pasteur, who contributed to the basic scientific understanding of microbiological processes of disease and developed practical applications to prevent the spoilage of vinegar, beer, wine, and milk. Research on college student motivation and learning should also adopt these twin goals of scientific understanding and practical applications. An important aspect of this type of use-inspired basic research is the development of strong conceptual models that can be readily tested and applied in different contexts (Pintrich, 2000a). The general conceptual model presented here may offer one framework that can help to guide future use-inspired research in the area of college student motivation and learning.

\section{REFERENCES}

Ajzen, I. (1988). Attitudes, Personality, and Behavior, Dorsey Press, Chicago.

Bandura, A. (1997). Self-Efficacy: The Exercise of Control, W.H. Freeman, New York.

Biggs, J. (1993). What do inventories of students' learning processes really measure? A theoretical review and clarification. Br. J. Educ. Psychol. 63:3-19.

Biggs, J. (2001). Enhancing learning: A matter of style of approach? In Sternberg, R., and Zhang, L. (eds.), Perspectives on Thinking, Learning, and Cognitive Styles, Erlbaum, Mahwah, NJ, pp. 73-102.

Boekaerts, M. (1993). Being concerned with well-being and with learning. Educ. Psychol. 28: 148-167.

Boekaerts, M., and Niemivirta, M. (2000). Self-regulated learning: Finding a balance between learning goals and ego-protective goals. In Boekaerts, M., Pintrich, P. R., and Zeidner, M. (eds.), Handbook of Self-regulation: Theory, Research, and Applications, Academic Press, San Diego, CA, pp. 417-450.

Boekaerts, M., Pintrich, P. R., and Zeidner, M. (2000). Handbook of Self-Regulation, Academic Press, San Diego, CA.

Bransford, J., Brown, A., and Cocking, R. (1999). How People Learn: Brain, Mind, Experience, and School, National Academy Press, Washington, DC.

Corno, L. (1993). The best-laid plans: Modern conceptions of volition and educational research. Educ. Res. 22: 14-22.

Dyne, A., Taylor, P., and Boulton-Lewis, G. (1994). Information processing and the learning context: An analysis from recent perspectives in cognitive psychology. Br. J. Educ. Psychol. 64: 359-372.

Eccles, J. S., Wigfield, A., and Schiefele, U. (1998). Motivation to succeed. In Damon, W. (Series ed.) and N. Eisenberg (Vol. ed.), Handbook of Child Psychology: Vol. 3. Social, Emotional, and Personality Development, 5th edn., Wiley, New York, pp. 10171095.

Entwistle, N., and Waterston, S. (1988). Approaches to studying and levels of processing in university students. Br. J. Educ. Psychol. 58: 258-265.

Garcia, T., McCann, E., Turner, J., and Roska, L. (1998). Modeling the mediating role of volition in the learning process. Contemp. Educ. Psychol. 23: 392-418.

Garcia, T., and Pintrich, P. R. (1994). Regulating motivation and cognition in the classroom: The role of self-schemas and self-regulatory strategies. In Schunk, D. H., and 
Zimmerman, B. J. (eds.), Self-Regulation of Learning and Performance: Issues and Educational Applications, Erlbaum, Hillsdale, NJ, pp. 127-153.

Gollwitzer, P. (1996). The volitional benefits of planning. In Gollwitzer, P., and Bargh, J. (eds.), The Psychology of Action: Linking Cognition and Motivation to Behavior, Guilford Press, New York, pp. 287-312.

Hofer, B., Yu, S., and Pintrich, P. R. (1998). Teaching college students to be self-regulated learners. In Schunk, D. H., and Zimmerman, B. J. (eds.), Self-Regulated Learning: From Teaching to Self-Reflective Practice, Guilford Press, New York, pp. 57-85.

Howard-Rose, D., and Winne, P. (1993). Measuring component and sets of cognitive processes in self-regulated learning. J. Educ. Psychol. 85(4): 591-604.

Karabenick, S., and Sharma, R. (1994). Seeking academic assistance as a strategic learning resource. In Pintrich, P. R., Brown, D. R., and Weinstein, C. E. (eds.), Student Motivation, Cognition, and Learning: Essays in Honor of Wilbert J. McKeachie, Erlbaum, Hillsdale, NJ, pp. 189-211.

Kuhl, J. (1984). Volitional aspects of achievement motivation and learned helplessness: Toward a comprehensive theory of action control. In Maher, B., and Maher, W. (eds.), Progress in Experimental Personality Research, Vol. 13, Academic Press, New York, pp. 99-171.

Lonka, K., and Lindblom-Ylanne, S. (1996). Epistemologies, conceptions of learning, and study practices in medicine and psychology. Higher Educ. 31: 5-24.

Marton, F., and Saljo, R. (1976). On qualitative differences in learning: I. Outcome and process. Br. J. Educ. Psychol. 46: 4-11.

McKeachie, W. J., Pintrich, P. R., and Lin, Y. G. (1985). Teaching learning strategies. Educ. Psychol. 20: 153-160.

Messick, S. (1989). Validity. In Linn, R. L. (ed.), Educational Measurement, 3rd edn., Macmillan, New York, pp. 13-104.

Midgley, C., Arunkumar, R., and Urdan, T. (1996). "If I don't do well tomorrow, there's a reason": Predictors of adolescents' use of academic self-handicapping strategies. J. Educ. Psychol. 88: 423-434.

Newman, R. (1998). Adaptive help seeking: A role of social interaction in self-regulated learning. In Karabenick, S. (ed.), Strategic Help-Seeking: Implications for Learning and Teaching, Erlbaum, Hillsdale, NJ, pp. 13-37.

Norem, J. K., and Cantor, N. (1986). Defensive pessimism: Harnessing anxiety as motivation. J. Pers. Soc. Psychol. 51: 1208-1217.

Pintrich, P. R. (1999a). Taking control of research on volitional control: Challenges for future theory and research. Learn. Individ. Differ. 11: 335-354.

Pintrich, P. R. (1999b). The role of motivation in promoting and sustaining self-regulated learning. Int. J. Educ. Res. 31: 459-470.

Pintrich, P. R. (2000a). Educational psychology at the millennium: A look back and a look forward. Educ. Psychol. 35: 221-226.

Pintrich, P. R. (2000b). The role of goal orientation in self-regulated learning. In Boekaerts, M., Pintrich, P. R., and Zeidner, M. (eds.), Handbook of Self-Regulation, Academic Press, San Diego, CA, pp. 451-502.

Pintrich, P. R., and De Groot, E. V. (1990). Motivational and self-regulated learning components of classroom academic performance. J. Educ. Psychol. 82: 33-40.

Pintrich, P. R., McKeachie, W., and Lin, Y.-G. (1987). Teaching a course in learning to learn. Teach. Psychol. 14: 81-86.

Pintrich, P. R., and Schunk, D. H. (2002). Motivation in Education: Theory, Research and Applications, Prentice Hall Merrill, Upper Saddle River, NJ.

Pintrich, P. R., Smith, D., Garcia, T., and McKeachie, W. (1991). A Manual for the Use of the Motivated Strategies for Learning Questionnaire (MSLQ), The University of Michigan, Ann Arbor, MI.

Pintrich, P. R., Smith, D., Garcia, T., and McKeachie, W. (1993). Predictive validity and reliability of the Motivated Strategies for Learning Questionnaire (MSLQ). Educ. Psychol. Meas. 53: 801-813. 
Pintrich, P. R., Wolters, C., and Baxter, G. (2000). Assessing metacognition and self-regulated learning. In Schraw, G., and Impara, J. (eds.), Issues in the Measurement of Metacognition, Buros Institute of Mental Measurements, Lincoln, NE.

Pressley, M., and Afflerbach, P. (1995). Verbal Protocols of Reading: The Nature of Constructively Responsive Reading, Erlbaum, Hillsdale, NJ.

Ryan, A., and Pintrich, P. R. (1997). "Should I ask for help?" The role of motivation and attitudes in adolescents' help seeking in math class. J. Educ. Psychol. 89: 329-341.

Sansone, C., Weir, C., Harpster, L., and Morgan, C. (1992). Once a boring task, always a boring task? The role of interest as a self-regulatory mechanism. J. Pers. Soc. Psychol. 63: 379390.

Schneider, W., and Pressley, M. (1997). Memory Development Between 2 and 20, Erlbaum, Mahwah, NJ.

Schunk, D. H., and Ertmer, P. (2000). Self-regulation and academic learning: Self-efficacy enhancing interventions. In Boekaerts, M., Pintrich, P. R., and Zeidner, M. (eds.), Handbook of Self-Regulation, Academic Press, San Diego, CA, pp. 631-649.

Simpson, M., Hynd, C., Nist, S., and Burrell, K. (1997). College academic assistance programs and practices. Educ. Psychol. Rev. 9: 39-87.

Snow, R., Corno, L., and Jackson, D. (1996). Individual differences in affective and conative functions. In Berliner, D., and Calfee, R. (eds.), Handbook of Educational Psychology, Macmillan, New York, pp. 243-310.

Stokes, D. (1997). Pasteur's Quadrant: Basic Science and Technological Innovation, Brookings Institute, Washington, DC.

Trigwell, K., Prosser, M., and Waterhouse, F. (1999). Relations between teachers' approaches to teaching and student approaches to learning. Higher Educ. 37: 57-70.

VanderStoep, S., Pintrich, P. R., and Fagerlin, A. (1996). Disciplinary differences in selfregulated learning in college students. Contemp. Educ. Psychol. 21: 345-362.

Vermetten, Y., Lodewijks, H., and Vermunt, J. (1999). Consistency and variability of learning strategies in different university courses. Higher Educ. 37: 1-21.

Vermunt, J. (1996). Metacognitive, cognitive, and affective aspects of learning styles and strategies: A phenomenographic analysis. Higher Educ. 31: 25-50.

Weiner, B. (1986). An Attributional Theory of Motivation and Emotion, Springer-Verlag, New York.

Weinstein, C., and Mayer, R. (1986). The teaching of learning strategies. In Wittrock, M. (ed.), Handbook of Research on Teaching and Learning, Macmillan, New York, pp. 315327.

Weinstein, C., Zimmermann, S., and Palmer, D. (1988). Assessing learning strategies: The design and development of the LASSI. In Weinstein, C., Goetz, E., and Alexander, P. (eds.), Learning and Study Strategies: Issues in Assessment, Instruction, and Evaluation, Academic Press, San Diego, CA, pp. 25-40.

Winne, P., and Hadwin, A. (1998). Studying as self-regulated learning. In Hacker, D., Dunlosky, J., and Graesser, A. (eds.), Metacognition in Educational Theory and Practice, Erlbaum, Hillsdale, NJ, pp. 279-306.

Winne, P., Jamieson-Noel, D., and Muis, K. (2001). Methodological issues and advances in researching tactics, strategies, and self-regulated learning. In Pintrich, P. R., and Maehr, M. L. (eds.), Advances in Motivation and Achievement: Vol. 12. New Directions in Measures and Methods, JAI Press Elsevier Science, Amsterdam, pp. 121-155.

Winne, P., and Perry, N. (2000). Measuring self-regulated learning. In Boekaerts, M., Pintrich, P. R., and Zeidner, M. (eds.), Handbook of Self-Regulation, Academic Press, San Diego, CA, pp. 531-566.

Wolters, C. (1998). Self-regulated learning and college students' regulation of motivation. J. Educ. Psychol. 90: 224-235.

Wolters, C., and Pintrich, P. R. (1998). Contextual differences in student motivation and selfregulated learning in mathematics, English, and social studies classrooms. Instr. Sci. 26: $27-47$.

Zeidner, M. (1998). Test Anxiety: The State of the Art, Plenum, New York. 
Zimmerman, B. J. (1998). Academic studying and the development of personal skill: A selfregulatory perspective. Educ. Psychol. 33: 73-86.

Zimmerman, B. J. (2000). Attaining self-regulation: A social cognitive perspective. In Boekaerts, M., Pintrich, P. R., and Zeidner, M. (eds.), Handbook of Self-Regulation: Theory, Research, and Applications, Academic Press, San Diego, CA, pp. 13-39.

Zimmerman, B. J., and Martinez-Pons, M. (1986). Development of a structured interview for assessing student use of self-regulated learning strategies. Am. Educ. Res. J. 23: 614-628. 